\title{
Feasibility Study of Adaptation of Biomimicry Approach in Green Building
}

\author{
Mahesh Bankar ${ }^{l, *}$, Vishakha Jogdand ${ }^{2}$ \\ ${ }^{1}$ Maharashtra Institute of Technology, Aurangabad \\ ${ }^{2}$ CSMSS'S Chhatrapati Shahu College of Engineering, Aurangbad.
}

\begin{abstract}
This paper deals with adaptation of Biomimicry strategies in building to make it environmentally sustainable. Biomimicry is the innovative approach which emulates the design principles of Flora and fauna as the genesis of the design. The approach is studied in context with the objectives of green building viz., Indoor air quality, Water efficiency, Energy efficiency and eco-friendly HVAC system. The study investigates the potential of emulating Biomimicry approach in green building technology. In this paper it is discussed that how the Biomimicry approach innovatively solves the purpose of green building, i.e. Resource efficiency and reduce environmental impact of the building.
\end{abstract}

\section{Introduction}

Out of total global emission, $26 \%$ is caused by buildings. Enormous amount of materials and resources viz., electricity, water, material, and energy are consumed by building sector. [1] At the same time, building sector has great potential of significant reduction of emission and environmental impact. The need of Green building raises here. Green building is the practice to build structure which is environmentally friendly and resource efficient throughout its life cycle. i.e., from designing to construction and from renovation to demolition according to U.S Environmental Protection Agency. The practice broadens to comfort, durability and well-being of occupant. Material Efficiency, Water efficiency, Energy efficiency, Enhancing Indoor Environment Quality are some of the core objectives of Green building.[2] In Indian context, The IGBC (Indian Green Building Council) Green Interior Rating System, Version 1.0, 2015 provides the design and construction specifications of green building. [3]

Green building combines different approaches and technological approaches to satisfy its objectives. One of the advanced approaches is Biomimicry. It is the study and emulation of the design principle of flora and fauna i.e., natural constituents and processes to find the solution of human design problems. Thus Biomimicry approach utilize the natural elements and processes as "Model, Mentor and Measure" and adapt the techniques in all levels of design.[4] There are two categories in which Biomimicry approach is divided. First category is solving the design problem by identifying the principle with which another organism or an ecosystem solves it. It is conceptualized as "Design looking to Biology". Second is to solve the human design problem by identifying a particular behaviour, principle, function or characteristic in ecosystem or in an organism. It is conceptualized as "Biology influencing design". [5] The three levels of Biomimicry approach are Organism level, Behaviour level and ecosystem level. Organism level refers to adaption of working principle of a particular organism such as plant and animal in part or whole in design process. Behaviour level refers to adaption of simple natural element's behaviour (air, water, etc.) in design. Ecosystem level includes adaptation of the working baseline of whole ecosystem in designing or solving a particular problem.

This study explores the potential of Biomimicry concept in order to achieve the objectives of green building. In Indoor air quality improvements, the selective plants naturally remove the Volatile Organic Carbons from the air and improve the air quality. In water efficiency natural principle i.e., increase in the volume of water by mixing the air is used and a faucet aerator is designed which saves the water from a building maintaining the same water pressure. In energy efficiency, the new kind of Light Emitting Diodes (LED) lights inspired from lantern of a firefly potentially improves the illumination efficiency of light and subsequently reducing the demand of the number of indoor lights; reducing the power consumption of the building for indoor lighting. And an eco-friendly HVAC system inspired from the air flow mechanism of termite mount not only provides the adequate ventilation to achieve the occupant's comfort level but also solve the purpose of energy efficiency too. It also finds the compatibility of Biomimcry approach in Green building in IGBC's rating system.

\footnotetext{
*Corresponding author: msbankar365@gmail.com
} 


\section{Incorporation of Biomimcry in Green Building}

The Biomimicry in green building is used at various levels. To evaluate the potential of Biomimicry approach adaptation in Green Building, the building is identified. The identified building is Guest house of Maharaja Sayajirao University of Baroda, Vadodara, Gujarat, India. Feasibility of Biomimicry is studied for following objectives,

\subsection{Biomimicry in Indoor Air Quality (IAQ)}

Benzene, Trichloroethylene, and formaldehyde are major VOCs emitted from the indoor products like waxed papers, furniture waxes, cleaning products, varnishes, and adhesives, rubber, paints plastics grocery bags, printing inks, disinfectants, paints, lacquers, and cosmetics, , facial tissues, and paper towels, gasoline, oils. Plants remove the VOCs. The leaves and roots of plants absorb the pathogens and VOCs. The microbes in the plants break them down and destroy them, by converting the air pollutants into new plant tissues. $[6,7]$ Hence incorporation of the indoor plants can be done according to the credit no. 6 of IGBC Green Interior Rating system, Version 1.0, 2015 which suggests providing one indoor plant for every 100 sq.ft.[3] The five best plants suggested in the IGBC Green Interior Rating system, Version 1.0, 2015's annexure 3, Chemical vapour removal rating, requirement of light, difficulty to grow and removal of all three major VOCs $[6,7]$ are Janet Craig, English Ivy, Peace Lily, Bamboo Palm, Dragon tree. (See Fig. 1) Incorporation of plants in indoor environment explores second type of Biomimicry i.e., adopting specific aspect of flora and fauna. It is also an organism level of the biomimicry. Hence it has great significance in improving indoor air quality.

To check the feasibility of Biomimicry in Indoor Air Quality improvement, first the total carpet area is calculated in order to find numbers of plants to be provided in each building spaces according to compliance standard given in IGBC GIRS - Indoor Environment Credit no. 6. It states that for every 100 sq. Ft of carpet area at least one plant should be provided. Then Indoor plants are selected on the basis of requirement of light, step number one, Chemical vapours removal rating, and removal of all three major VOCs and difficulty to grow. $[5,6]$ The plants are provided in different section of the building. Aesthetic liberty is considered for provision of plants. Then total removal of the three major VOCs; Trichloroethylene, Benzene and Formaldehyde by the total surface area of the provided plants for $24 \mathrm{hr}$ of exposure is evaluated on the basis of report of NASA [7]. Finally gain in points of IGBC GIRS - Indoor Environment credit 6 is evaluated in order to prove the acceptability of the Biomimetic approach in Indoor Environment.

\subsection{Biomimicry and water efficiency}

According to U.S Environmental Protection Agency, "water efficiency is smart use of the water resources through water saving technologies. Using water efficiently will help ensure reliable water supplies today and for future generation". A simple device is designed from inspiring from the simple natural principle; Volume of water increases when air is mixed in it. This is the second type (Biology influencing design) and Behavioural level Biomimicry. The air is drawn into the water stream breaking the stream into the tiny droplets mixed with air. The mixture of water and air passes through the screen and further mix the water and air which evenly spread out the resulting stream. Because there is less space of water to flow through, the water flow is reduced but water pressure is maintained and users don't notice the amount of water coming out of the aerator. This phenomenon saves the water. A structure of typical faucet aerator is given in fig 1 .

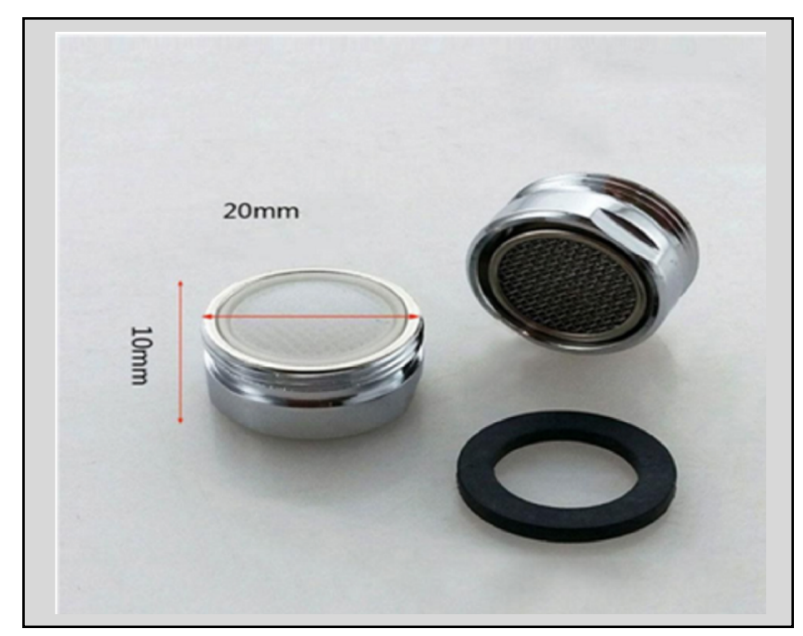

Fig.1.Faucet aerator

The Water efficiency credit criteria 1 of IGBC's Green Interior Rating system, Version 1.0, 2015 suggests to use the water fixtures with minimum $10 \%$ and maximum $40 \%$ less water flow rate than the standard baseline flow rate of the building according to uniform plumbing code, India-2008. For Water tap, baseline flow rate is 8 Liters per Minute. [8] In the market the faucet taps with flow rate of 6 to 4 Liters per Minute are available.

To study the feasibility of faucet aerator in identified building, total water consumption of the building is evaluated on the basis of number of occupants. The baseline flow rate of the water fixtures of the building is as per Uniform Plumbing Code- India, 2008. Then potential water saving is evaluated by replacing the current water fixture with the Biomimetic water fixture. Credit gained by only faucet aerator is evaluated on the basis of IGBC Green Interior Rating system's WE Cr 1.

Then the water saving potential is evaluated using additional water efficient water fixtures for checking the feasibility of Biomimetic technique in combination with modern water efficient technique. The total saving in water with the use of both the water efficient techniques 
is evaluated. Cost associated with the Biomimetic water fixture and modern water efficient water fixtures are evaluated. Finally, total IGBC credit gain is evaluated.

\subsection{Biomimicry and Energy efficiency}

Highly efficient Bioluminescent lighting system of fireflies inspired researchers to create an antireflection lens for Light Emitting Diode (LED). A firefly lantern is an organ in firefly to deliver an optical signal. A lantern organ is enclosed around the abdominal consist of 1) Cuticle, 2) Photogenic layer 3) Dorsal layer. (See Fig. 2).

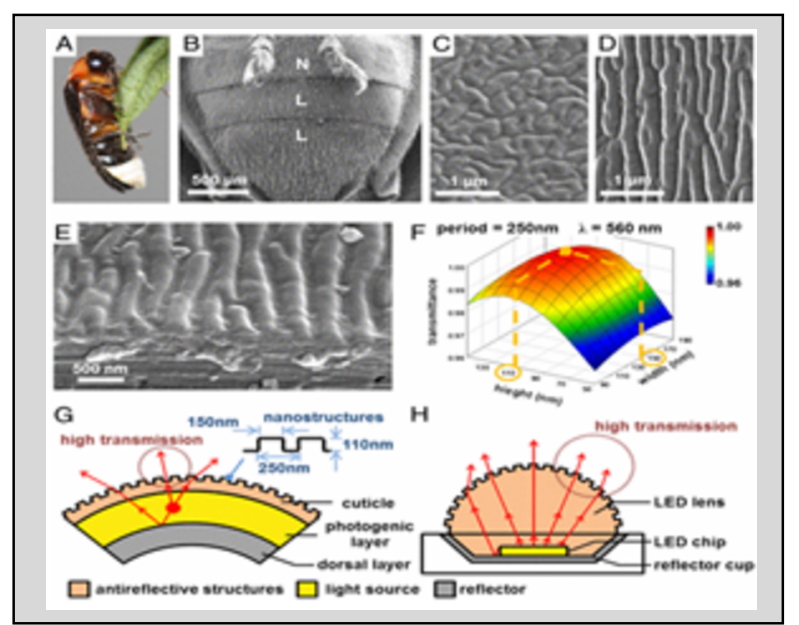

Fig.2.Highly ordered cuticular nanostructures of a firefly light organ inspiring the design of New LED.

In figure 3 observe, A: The optical image of a firefly in male, B: The SEM image of abdominal segment of a firefly in male including Normal $\mathrm{N}$, and lantern (L), cuticles, C: amorphous nanostructure on the normal cuticle, D: Highly ordered nanostructure on the lantern cuticle, E: A transverse cross section of the light organ, F: Transmission of bioluminescent light through nanostructured surface on the lantern cuticle calculated by FDTD method, G: A firefly lantern, H: A high power LED package.

Bioluminescent light in all directions is emitted by the photogenic layer which passes through cuticle after reflecting off the dorsal layer. Highly ordered circular nanostructures surrounding veterans photogenic layer reduce the index mismatch between cuticle surface andair to have high extraction of bioluminescent light in all directions. The different space patterns created by each nanostructure cause the light to form pattern in different directions which reduce the loss of amount of light due to internal reflection. [9] The LED light have same configuration. It consists of reflector cup, LED chip and LED lenses. The light is emitting through LED chips and finally extracted either by reflecting from reflection cup or LED lens. Thus, new nanostructure LED lenses are discovered which reduce the index mismatch between air and lens material. These LED lights have $55 \%$ more emitting efficiency than conventional LED lights.

Hence for a particular building after finding the adequate illumination requirement to maintain visual comfort, these new kinds of LED lights can be provided. As the LED lights gives more light emitting efficiency the requirement of number of LED lights is reduced. This phenomenon can automatically reduce the consumption of the electricity contributing the objective of energy efficiency. This is the first category of Biomimicry and organism level of Biomimicry as it is directly adopting principle of the firefly.

To analyse the potential of this phenomenon, first evaluation of Lumen required as per Illuminating Engineering Society code of Lighting is done for each section of building. Then identification of Carpet area is done for evaluation of required illumination in each room of the building. Evaluation of standard LED light fixture is done assuming the standard LED light of 1100 lumen for No of lights, Energy consumption and cost associated. Evaluation of Biomimetic LED light Fixture is done assuming 55\% more illumination than standard LED light fixture for No of lights, Energy consumption, Cost associated. Then comparison of Standard LED lights and Biomimetic LED lights is done on the basis of No of lights, Energy consumption and cost. Finally, total Gain in IGBC Credits is evaluated to understand the suitability of this Biomimetic approach.

\subsection{Biomimicry and Energy efficiency}

Another prime objective of the green building is maintaining the optimum comfort of indoor occupants. To achieve the objectives various conventional HVAC technologies are used. These technologies are costly in installation, operation and along with have significant environmental impact. However, Biomimicry provide the new approach to design the HVAC system of a building.

Termites in Zimbabwe build huge mounds for their shelter. However, the optimum temperature of $30^{\circ} \mathrm{C}$ is maintained by constantly opening and closing a series of heating and cooling vents throughout the mount over the course of the day. Air is sucked in the lower part of the termite enclosing with muddy walls and vented up through the channel to the peak of termite mound. Observe fig 3. 


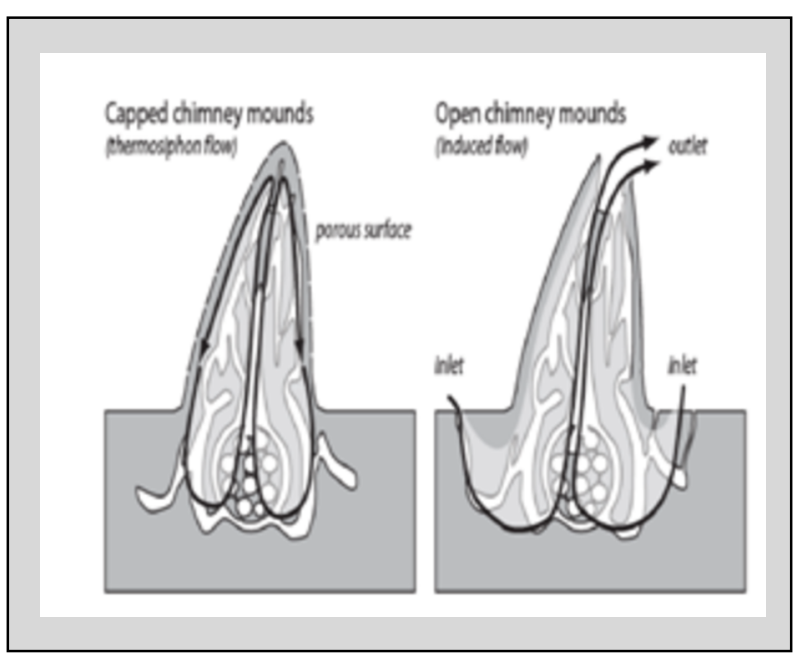

Fig.3.Air flow mechanism in termite mound

The air is sucked in the bottom section of mount, circulated in the mound and vented from the chimney. [10] The Eastgate Centre, Harare, Zimbabwe designed the ventilation system works same as that of the termite mount. Observe Fig. 4.

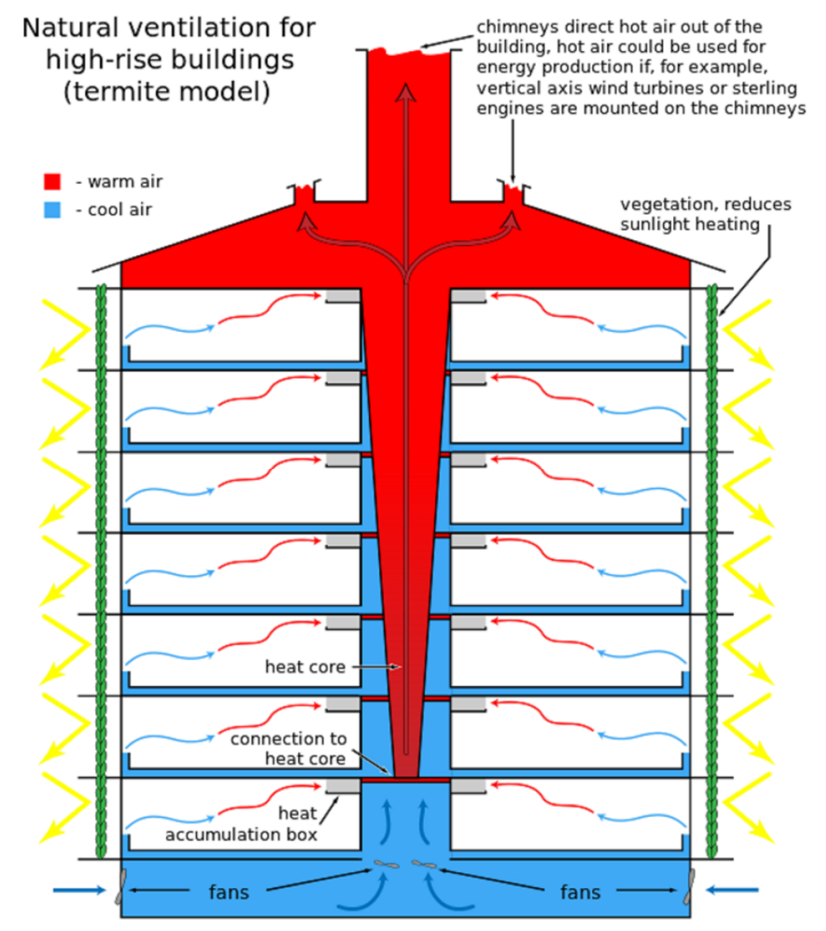

Fig.4.Air flow mechanism of Eastgate Centre, Harare, Zimbabwe

Air is continuously drawn from the open space by fans on first floor as shown in Fig. 5. It is then pushed up through vertical supply of the section of the duct located in central spine of each building. The fresh air replaces dead air that rises through and exit through exhaust ports. The exhaust ports are in the ceiling and through it flushed out of building through chimneys. As compared to same size conventional building the Eastgate centre uses less than $10 \%$ the energy. The owners also saved 3.5 million dollars alone because of this system. [10] Hence it is observed that the innovative HVAC system not only improves the air circulation of the building but also saves cost.

To check the potential of this phenomenon for identified building, first cooling load calculations is done in order to design the Biomimetic HVAC system and Conventional HVAC system. Then Biomimetic HVAC system designed on the basis of calculated cooling load. The system is evaporative cooling system supported by ducting. At the same time conventional HVAC system is designed for same identified building using same cooling load for comparison purpose. After that comparison of Conventional and Biomimetic HVAC system is done on the basis of Capital cost, Operational cost and Energy consumption. And finally, IGBC credit gain is evaluated for Biomimetic HVAC system.

\section{ResultsAnd Discussions}

From the study and evaluation, it is observed that Biomimicry approach in the Green Buildings plays a significant role. Following results are obtained from the study in identified aspects of green building.

\subsection{Indoor air quality enhancement}

It is observed that indoor plants have potential to remove the hazardous VOCs considerably. For the identified building, considering the carpet area 74 plants are required. However, 170 plants are provided considering aesthetic and Biophilic aspect. The plants selected and number of each plant provided are Bamboo palm (59), Janet Craig (22), English Ivy (62), Peace lily (10), and dragon tree (17). The total plants have potential to remove the major VOCs considerably and can enhance indoor air quality. For 24 hrs. of exposure, all provided plants having total surface area of $12,14,525$ sq.cm have potential of removing 25,82,566 ppm of Trichloroethylene (TCE). Similarly, with total surface area of $12,36,534$ sq.cm they have potential of removing $44,38,459 \mathrm{ppm}$ of Benzene while with total surface area of $14,49,182$ sq.cm potentially $31,58,169 \mathrm{ppm}$ of Formaldehyde can be removed. The total cost for provision of plants is Rs. 57,930. The provision of plants gains 2 points from IGBC's GIRS- Indoor Environment, Credit No.6. Also adequate ventilation provided by the Biomimicry principal inspired HVAC system helps to remove the indoor pollutants more effectively.

\subsection{Water Efficiency}

The water fixture of identified building is observed and replaced with Biomimicry inspired tap i.e., faucet aerator. For adequate water supply, the total daily 
maximum water demand of the occupant as per IS 1172:1993(2007) of identified building is 135 lit/capita/day i.e., $15862 \mathrm{lit} /$ day in total. However, for adequate water supply, baseline flow rate of the tap as per Uniform Plumbing Code- India, 2008 is 8 LPM and the estimated daily use is 4 minutes. Thus, by replacing the regular tap with biomimetic faucet aerator, the flow rate is reduced by 2 LPM i.e. 6 LPM. Hence the water saving from the saved flow rate is 8 litters/ capita/ day. The total water saving from required water is 752 lit/day. Also $11 \%$ flow rate is saved from baseline flow rate. Due to this, 1 point in IGBC Green Interior Rating System's Water Efficiency Credit 1, is gained. The total cost of the faucet aerators is Rs. 33,800. However to ensure more water saving and credit points to gain, the Water closets and the urinals are evaluated for replacements with water efficient closets and urinals. It is observed that the efficient water closets and waterless urinals save 6 LPF flow rate than total baseline flow rate. This is $33 \%$ of the total baseline flow rate. Also, both the fixtures save 752 litre of water of total requirement per day. The total cost of the additional water fixture is Rs. 46,500. Hence the biomimetic fixture and the additional efficient water fixture together, save 1052 litre of water per day. The total water fixture also saves $44 \%$ of the baseline flow helps gaining 13 points in IGBC's Green Interior Rating system; Water Efficiency Credit 1.

\subsection{Energy Efficiency}

Assumed conventional LED bulb of 15 Watts emits 1100 lumen of light. For the same wattage, assumption for biomimetic LED bulb emits 1700 lumen of light. Hence for identified building, to achieve the visual comfort of occupant. Total 167 conventional LED bulbs are required. The total cost of the conventional bulb is Rs. 33,400 . The total electricity cost is $2626.2 \mathrm{Rs} /$ month. For same criteria of illumination, 112 Biomimetic LED lights are required. The total cost of the Biomimetic LED lights is 29,130 Rs which is considered as same as 1700 lumen LED light's market price. The total electricity cost is $1753 \mathrm{Rs} /$ month. Hence, for the same illumination requirement less number of biomimetic LED bulbs is required, the capital cost is lower than conventional LED bulbs and the electricity consumption and cost is also less as compared to the conventional LED bulbs. It helps to gain 2 points in IGBC's Green Interior Rating System; Energy Efficiency Credit 2.

\subsection{HVAC system}

For identified building, new HVAC system is designed which is inspired from the biomimetic principle of the termite mount. The total cooling load to design HVAC system is $15 \mathrm{TR}$. The total Design air to be supplied in the spaces is $5036 \mathrm{cfm}$. HVAC system in fusion of evaporative cooling system and ducting system is designed. For same cooling load, the conventional but environmentally friendly 5 star split air conditioners are also identified. The total capital cost of the Biomimetic HVAC system considering all the components is Rs. 379,150 while the capital cost of the total conventional Split AC system is Rs. 531850. The electricity consumption cost of the split AC system for 4 months of summer and $24 \mathrm{hrs}$. operation is Rs. 26,35,77 while for same criteria electricity consumption of the Biomimetic HVAC system is Rs. 68080. Hence biomimetic system saves the capital cost and operational cost. The Biomimetic HVAC system gains 1 point of Energy Efficiency Credit 1, 8 points in Energy Efficiency Credit 2; Fulfils Mandatory requirement number 2 of Indoor Environment Credit, 2 points of Indoor Environment Credit 1 from IGBC Green Interior Rating System. Hence the Biomimetic HVAC system helps to gain 11 points in total of IGBC Green Interior Rating System.

Hence from overall study it is observed that Biomimicry helps to get the points in credit system of IGBC Green Interior Rating system by satisfying the criteria for it. Table 1 gives details of credits gain by Biomimicry

Table 1.Credit Gain by Biomimetic Green Building

\begin{tabular}{|l|l|l|l|l|}
\hline Title & $\begin{array}{l}\text { Credi } \\
\mathbf{t}\end{array}$ & $\begin{array}{l}\text { Credit } \\
\text { Name }\end{array}$ & $\begin{array}{l}\text { Availabl } \\
\text { e Points }\end{array}$ & $\begin{array}{l}\text { Achieve } \\
\text { d Points }\end{array}$ \\
\hline $\begin{array}{l}\text { Water } \\
\text { Efficiency }\end{array}$ & $\begin{array}{l}\text { WC } \\
\text { Credit } \\
1\end{array}$ & $\begin{array}{l}\text { Water } \\
\text { Conservatio } \\
\mathrm{n}\end{array}$ & 12 & 12 \\
\hline $\begin{array}{l}\text { Energy } \\
\text { Efficiency }\end{array}$ & $\begin{array}{l}\text { EE } \\
\text { Credit } \\
1\end{array}$ & $\begin{array}{l}\text { Eco-friendly } \\
\text { Refrigerants } \\
\text { \& Halons }\end{array}$ & 1 & 1 \\
\hline $\begin{array}{l}\text { Indoor } \\
\text { Environmen } \\
\mathbf{t}\end{array}$ & $\begin{array}{l}\text { EE } \\
\text { Credit }\end{array}$ & $\begin{array}{l}\text { Energy } \\
\text { Efficient } \\
\text { Interiors }\end{array}$ & 10 & 10 \\
\cline { 2 - 5 } & $\begin{array}{l}\text { IE } \\
\text { Credit } \\
1\end{array}$ & $\begin{array}{l}\text { Enhanced } \\
\text { Fresh Air } \\
\text { Ventilation }\end{array}$ & 2 & 2 \\
\hline \multicolumn{5}{|l}{ Total }
\end{tabular}

At certification level as Biomimicry is achieving 26 points, the identified building have potential to get recognition of Best practices as the criteria for it is to get points between $22-31$.

\subsection{Cost analysis}

To achieve the identified green building objectives, total cost required for conventional techniques is $128.55 \mathrm{Rs} /$ Sq.ft while total cost required for Biomimetic system is 100.78 Rs. It is observed that Biomimetic techniques save $21.62 \%$ cost as compared to conventional techniques in order to achieve the Green Building objectives viz., Indoor Air Quality, Water efficiency, Energy efficiency and Environmental friendly HVAC system. 


\section{Conclusion}

It can be concluded that Biomimicry approach increase the Indoor Air quality of the building by using indoor plants by removing 10179194 ppm VOCs. Biomimetic water fixture saves $6.63 \%$ of total daily water demand. Also, Biomimetic LED light fixtures save $33.26 \%$ of total monthly power demand for illumination. Biomimicry inspired HVAC system provides desired comfort, saves the capital cost by $28 \%$ and operational cost by $74.17 \%$ as compared to the conventional AC system to provide the indoor comfort. Provision of Biomimicry techniques along with the other efficient green building technologies has potential to gain 25 points of IGBC Green Interior Rating system as well as to amplify the building's resource efficiency and reduce its environmental impact. Along with advantages mentioned above, the cost of applying the Biomimicry technique for conventional building is resulting in saving $21.62 \%$ cost than conventional techniques to achieve the Green Building objectives.

\section{References}

1. U. Diana, IPCC, 4, 3, (2007)

2. D. Emily, N. Kriti, N. Zeenat, S. Andrew, D. Varsha and K. Vijaya Lakshmi , "Green Building- Case study”, ODI,1, 11,(2013)

3. IGBC, IGBC Green Int. Rating Syst., IGBC,1.0,51, (2015)

4. B. Janine M, Harper Perennial,1, 2-7, (2002).

5. Z.Maibrit, SB07,7, 3, (2013)

6. K. Kent, J. Andrew, G. John and M. James, furtherance of Cooperative Extension work, CTAHR,39, 4, ( 2007)

7. B. Wolverton, J. Anne, B. Keith, NASA, ALCA, (1989)

8. Indian Plumbing Association, Uniform plumbing code, IPC, 1, (2008)

9. E. Nour ,PES, 34, 375 -386, (2016) 